\title{
Multimodality cardiovascular imaging in pulmonary embolism
}

\author{
Hyung Yoon Kim ${ }^{1}$, Kye Hun Kim${ }^{1}$, Jahae Kim², Jong Chun Park ${ }^{1}$ \\ ${ }^{1}$ Department of Cardiovascular Medicine, Chonnam National University \\ Medical School/Hospital, Gwangju, Republic of Korea \\ ${ }^{2}$ Department of Nuclear Medicine, Chonnam National University \\ Medical School/Hospital, Gwangju, Republic of Korea
}

\begin{abstract}
Acute pulmonary embolism (APE) is one of the leading causes of cardiovascular (CV) morbidity and mortality. To select appropriate therapeutic strategy and/or to minimize the mortality and morbidity, rapid and correct identification of life-threatening APE is very important. Also, right ventricular (RV) failure usually precedes acute hemodynamic compromise or death, and thus the identification of $R V$ failure is another important step in risk stratification or treatment of APE. With advances in diagnosis and treatment, the prognosis of APE has been dramatically improving in most cases, but inadequate therapy or recurrent episodes of pulmonary embolism (PE) may result in negative outcomes or, so called, chronic thromboembolic pulmonary hypertension (CTEPH). CTEPH is a condition characterized by remaining chronic thromboembolic material in the pulmonary vasculature and subsequent chronic pulmonary hypertension.

Various imaging modalities include chest computed tomography pulmonary angiography (CTPA), echocardiography, magnetic resonance imaging, and nuclear imaging and each are used for the assessment of varying status of PE. Assessment of thromboembolic burden by chest CTPA is the first step in the diagnosis of PE. Hemodynamic assessment can be achieved by echocardiography and also by chest CTPA. Nuclear imaging is useful in discriminating CTEPH from APE.

Better perspectives on diagnosis, risk stratification and decision making in PE can be provided by combining multimodality $\mathrm{CV}$ imaging. Here, the advantages or pitfalls of each imaging modality in diagnosis, risk stratification, or management of PE will be discussed. (Cardiol J 2021; 28, 1: 150-160) Key words: pulmonary embolism, imaging
\end{abstract}

\section{Introduction}

Acute pulmonary embolism (APE) refers to a condition in which the pulmonary vasculatures are abruptly occluded by abnormal thrombi or emboli, usually originating from deep veins of the lower extremities. Because APE may result in right ventricular (RV) dysfunction and hemodynamic compromise, APE is one of the major causes of mortality worldwide [1, 2]. The rapid and correct diagnosis of APE is essential in selecting an appropriate therapeutic strategy and to reduce mortality from APE. In this regard, multi-modality cardiovascular $(\mathrm{CV})$ imaging, including chest computed tomography (CT), computed tomography pulmonary angiography (CTPA) and echocardiography are useful not only in the diagnosis of APE, but also in the evaluation of hemodynamic significance of APE

Address for correspondence: Kye Hun Kim, MD, PhD, Professor, Director of Echocardiography and Cardiovascular Imaging Laboratory, Director of Heart Failure Clinic, Director of Department of Cardiovascular Medicine, Chonnam National University Medical School/Hospital, 42 Jebong-ro, Dong-gu, Gwangju, 61469, Republic of Korea, tel: +82-62-220-6973 [office], fax: +82-62-227-4760, e-mail: cvkimkh@gmail.com; christiankyehun@hanmail.net

Received: 24.03.2019 Accepted: 20.08.2019

This article is available in open access under Creative Common Attribution-Non-Commercial-No Derivatives 4.0 International (CC BY-NC-ND 4.0) license, allowing to download articles and share them with others as long as they credit the authors and the publisher, but without permission to change them in any way or use them commercially. 

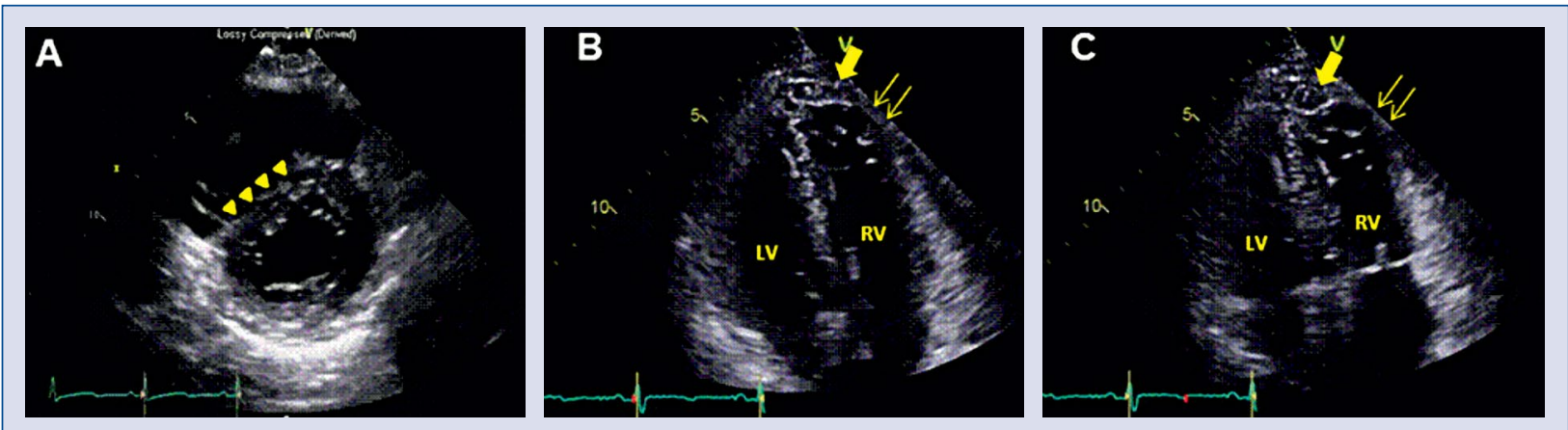

Figure 1. Transthoracic echocardiography demonstrating right ventricular (RV) dysfunction. D-shaped left ventricle (LV) (arrowheads) on parasternal short axis view represents RV pressure overload (A). RV enlargement and free wall hypokinesia with sparing of apical wall motion (McConnell's sign) on apical four-chamber view (B. At diastole; C. At systole).

and thus clinical decision making and therapeutic strategy [3]. The evaluation of therapeutic efficacy is another important role of CV imaging in APE.

With the advances in diagnosis, treatment and prognosis of APE has been dramatically improved in most of cases. Inadequate therapy or recurrent episodes of pulmonary embolism (PE) may result in a serious negative outcomes, including so called chronic thromboembolic pulmonary hypertension (CTEPH). Although the pathogenesis of CTEPH is not completely understood, unresolved organized fibrotic thrombi or emboli, subsequent endothelial dysfunction and abnormal vascular remodeling seem to be involved in the development of pulmonary hypertension (PH). In case of CTEPH, RV can initially adapt to the increased afterload by $\mathrm{PH}$ through the process of RV dilatation and hypertrophy, but a progressive or sustained significant increase of pulmonary artery pressure results in RV failure and death [4]. Contrary to the evanescent role of nuclear imaging in APE, ventilation/ perfusion $(\mathrm{V} / \mathrm{Q})$ scan is an imaging of choice in the detection of CTEPH [5].

In this review, the advantages and pitfalls of each imaging modality in diagnosis, risk stratification, and/or management of PE will be discussed.

\section{Role of TTE}

Although transthoracic echocardiography (TTE) is the most widely used CV imaging modality in the assessment of cardiac function and structure, it plays a limited role in the diagnosis of APE because TTE cannot directly visualize the location or extent of pulmonary arterial thrombi or emboli in many cases. However, TTE has a critical role in evaluating hemodynamic significance of APE, including RV dysfunction, and thus TTE is the most useful CV imaging modality in risk stratification, clinical decision making of therapeutic strategy, or evaluating the prognosis of APE [6]. Furthermore, TTE can provide the first indications for diagnosing APE frequently, because it is the most widely used $\mathrm{CV}$ imaging modality in patients with dyspnea or chest pain.

The presence of RV dysfunction in APE is a hallmark of higher risk patients and an independent predictor of adverse clinical outcomes, and sometimes it can advocate emergency reperfusion treatment for APE. Therefore, the echocardiographic evaluation of RV function is an important step in the evaluation of APE [7]. Echocardiographic findings suggesting RV dysfunction include RV dilatation, hypokinesia or akinesia of the RV free wall and relative sparing of RV apical wall motion (Mc Connell's sign), decreased tricuspid annulus plan systolic excursion (TAPSE) or fractional area change (FAC), and diminished RV longitudinal strain (Fig. 1) [8-13]. In addition, an increased RV systolic pressure assessed by measuring the peak velocity of tricuspid regurgitation (TR) jet or the increased size of the inferior vena cava or the change of an inferior vena cava size of less than $50 \%$ with inspiration can be a supportive sign of RV dysfunction [14]. Despite RV hypokinesia and PH, RV hypertrophy is not a finding of APE because of the acute nature of the illness. Contrary to APE, $\mathrm{RV}$ hypertrophy with moderate to severe $\mathrm{PH}$ is a common finding in CTEPH as a consequence of adaptation of RV to an elevated afterload. Accordingly, RV hypertrophy on TTE is a simple qualitative clue for chronic PE [15].

In summary, the role of TTE in PE can be summarized as follows; 1) TTE is an imaging of choice 


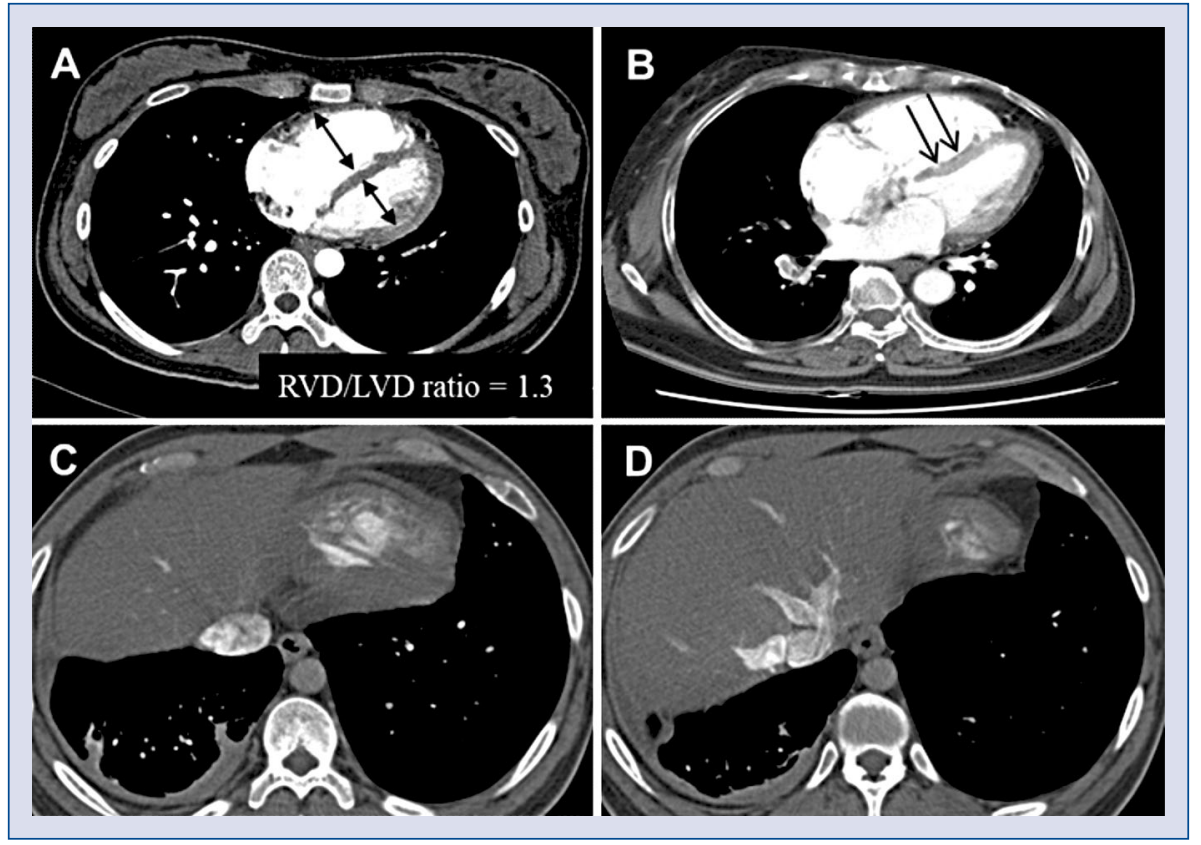

Figure 2. Chest computed tomography angiography suggesting right ventricular (RV) dysfunction. RV dimension is greater than left ventricular dimension (A). Leftward ventricular septal bowing (B). Contrast reflux (arrows) to the inferior vena cava (C) and hepatic veins (D).

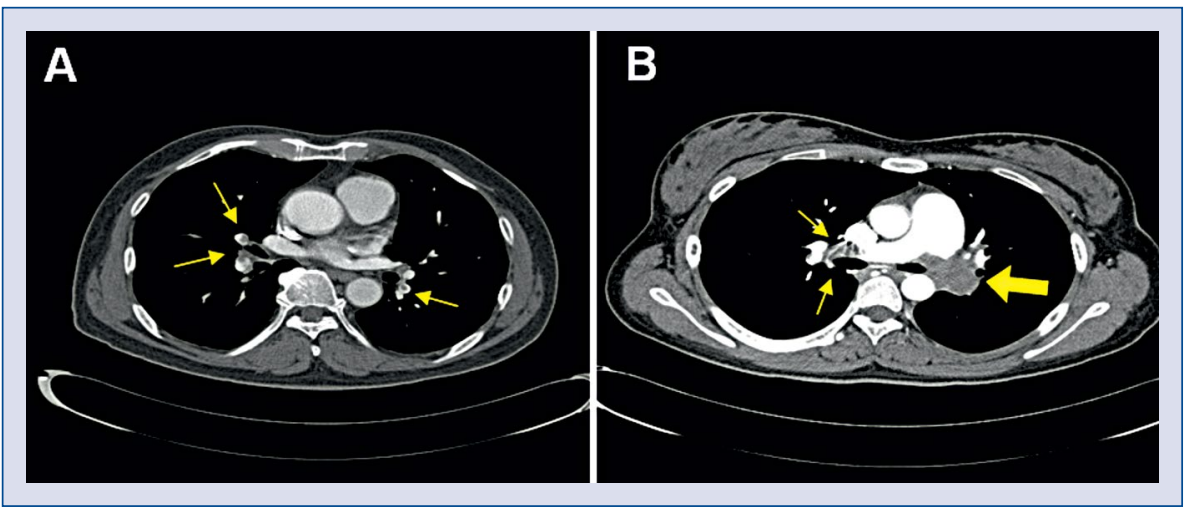

Figure 3. Chest computed tomography angiography shows multifocal small filling defects in both pulmonary arteries (arrows) (A) and large filling defects resulting in near total occlusion of the left pulmonary artery (wide arrow) and filling defect in right pulmonary artery (narrow arrow) (B).

in the evaluation of hemodynamic significance including RV dysfunction and thus risk stratification or clinical decision making of therapeutic strategy of known APE; 2) TTE can provide the first indication for suspecting APE in some patients; 3) RV hypertrophy with $\mathrm{PH}$ in patients with known $\mathrm{PE}$ may suggest a finding of CTEPH.

\section{Chest CTPA}

Rapid availability and reliability in diagnosis, has made chest CTPA the gold standard CV im- aging for the evaluation of suspected APE, and actually it replaced the role of the $\mathrm{V} / \mathrm{Q}$ scan in the diagnosis of APE. According to the PIOPED (Prospective Investigation of Pulmonary Embolism Diagnosis) II trial, CTPA appeared to have high negative predictive value (96\%) in patients with low clinical probability for APE and also has a high positive predictive value $(96 \%)$ in patients with high clinical probability for APE [16]. Hence, current guidelines recommend performing CTPA in patients highly suspected for APE or even in patients with low to intermedi- 
ate clinical probability for APE when they have hypotension or shock.

Besides the role in diagnosing APE, chest CTPA can provide information about hemodynamic significance of APE. Previous studies have shown that RV enlargement of chest CTPA is a marker for RV dysfunction in patients with APE (Fig. 2A) [17, 18]. RV enlargement can be evaluated by measuring right ventricular dimension to left ventricular dimension (RVD/LVD) ratio in a 4-chamber view of the chest CTPA, and RVD/LVD ratio greater than 1.0 is suggested as a reliable marker for RV dysfunction in a meta-analysis [19]. RVD/LVD ratio greater than 0.9 on chest CTPA was used as a marker for RV dysfunction in another prospective cohort study [20]. In a previous study, the optimal cut-off value of RVD/LVD ratio on CTPA for predicting RV dysfunction was 1.12 [21]. Leftward ventricular septal bowing and contrast reflux to the inferior vena cava on CTPA are also considered as suggestive findings of RV dysfunction in APE (Fig. 2B-D), but the diagnostic sensitivity and/or specificity of these findings are lower than those of RVD/LVD ratio. For these reasons, the measurement of RVD/LVD ratio has proved to be the most reliable predictor of mortality in patients with APE among CTPA measurements [21-23].

Chest CTPA also enables assessment of the presence, location, and degree of thrombi burden in APE (Fig. 3). Several scoring systems have been developed to evaluate the severity of a current episode of APE by measuring PA clot loads (Table 1) [24-28]. Qanadli index is a scoring system that evaluates the embolic burden by combining the total number of involved pulmonary vascular segments and degree of embolic obstruction [25]. Some studies demonstrated that the Qanadli index was a good predictor of RV dysfunction or mortality in APE, but it was not a predictor of RV dysfunction or mortality from APE in other studies [29-32]. Therefore, the clinical significance of these pulmonary artery clot load scoring systems for the prediction of RV dysfunction or mortality in patients with APE should be clarified through further and larger studies.

With recent advances in processing of $\mathrm{CT}$ images, dual energy CT (DECT) has become available for the assessment of pulmonary parenchyma perfusion, by using iodine-subtraction techniques [33]. Perfusion defect or hypo-perfused region corresponding to the vascular obstruction is indicative of PE (Fig. 4). Thus, DECT can be useful in the assessment of PE without evidence of overt thrombus on CTPA. However, the diagnostic or
Table 1. Various scoring systems assessing pulmonary arterial clot load

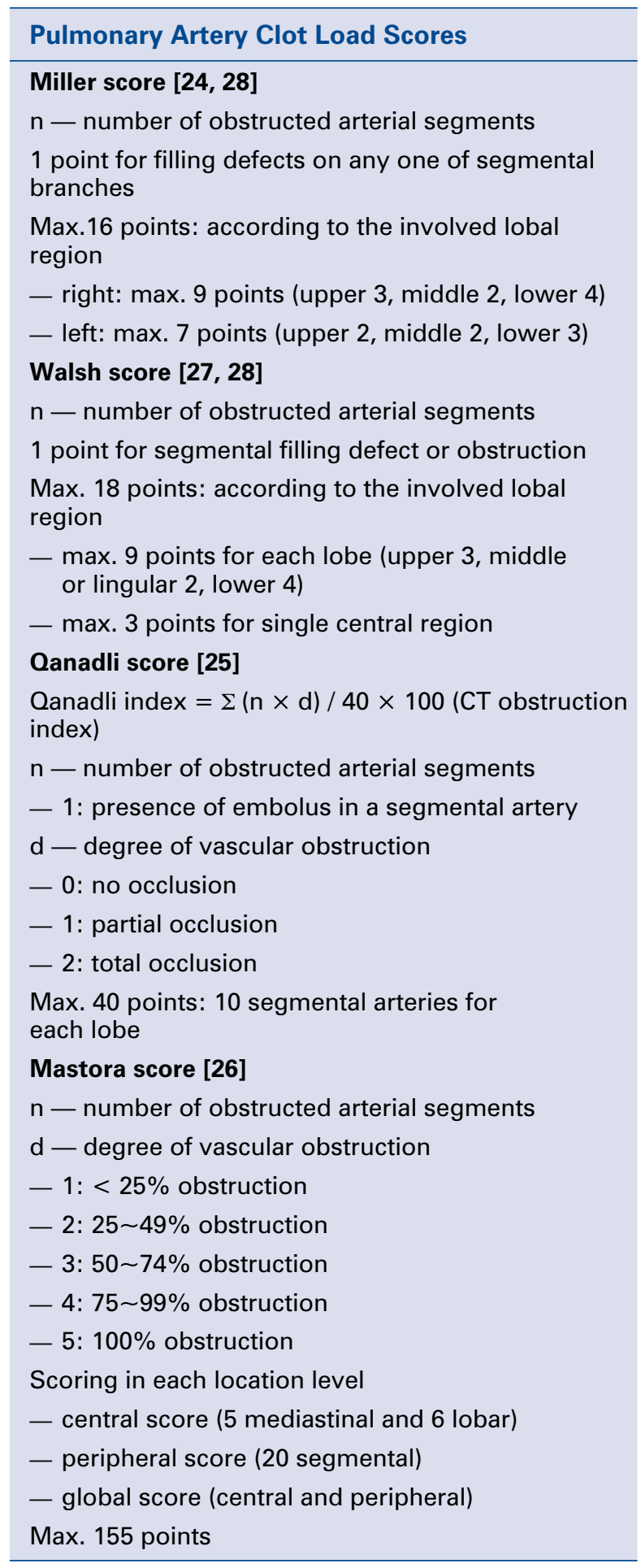

Max — maximal; CT — computed tomography

prognostic role of DECT in APE remains poorly defined. Further research should be conducted to investigate the role of quantitative DECT on clinical outcomes in patients with APE. 


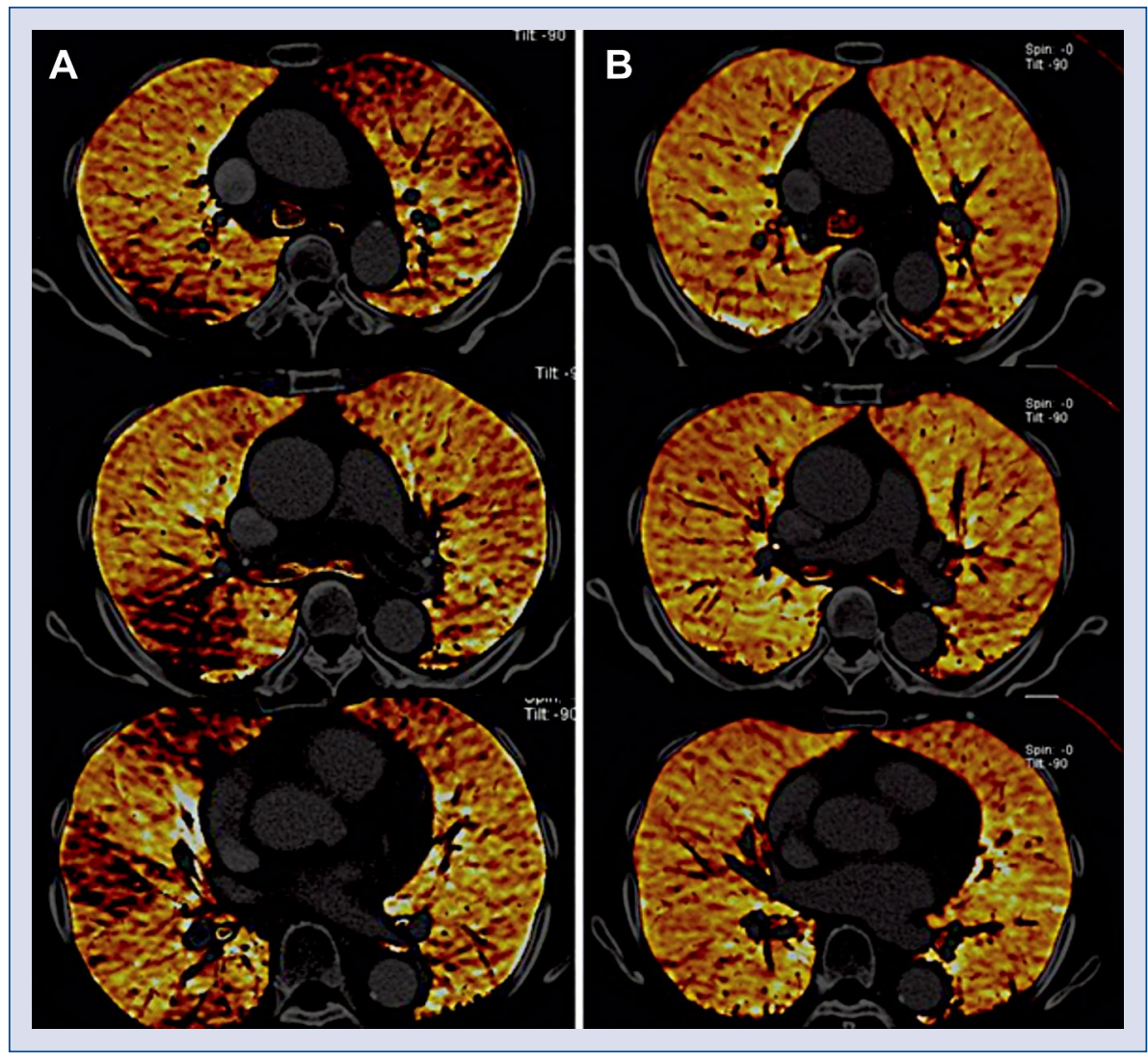

Figure 4. Dual energy computed tomography (DECT) in a 55-year-old female with acute pulmonary embolism. Pretreatment DECT shows multi-focal hypoperfused regions (dark-brown color) corresponding to the location of vascular obstruction (A). Follow up DECT shows the disappearance of hypoperfused regions after 6-months of anticoagulation (B).

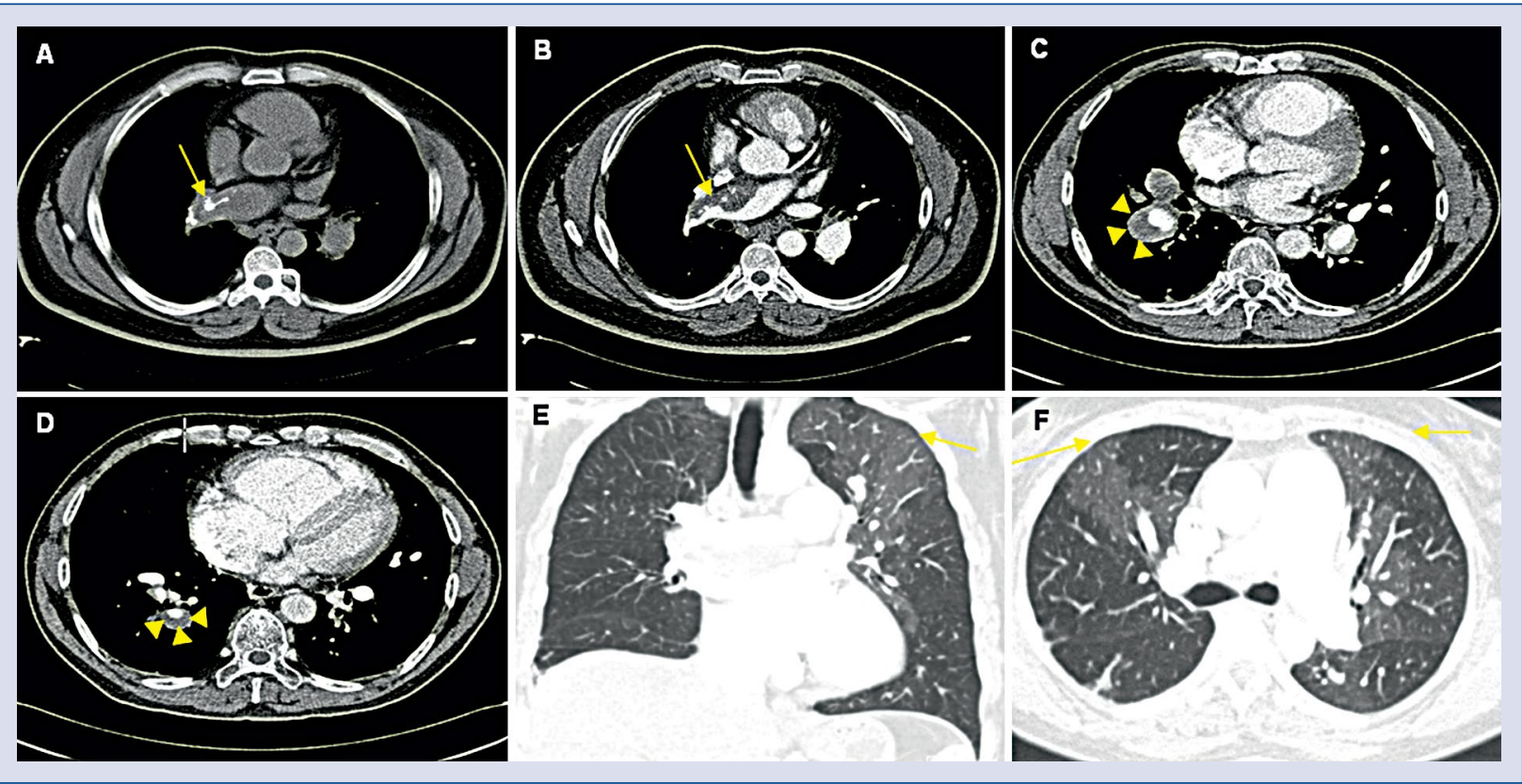

Figure 5. Chest computed tomography angiography (CTPA) suggesting chronic thromboembolic pulmonary hypertension. Calcific thrombi (arrows) in right pulmonary artery on pre-enhance (A), post-enhance CTPA (B), eccentric (crescentic shape) thrombi (arrow heads; C, D), and nonuniform arterial perfusion pattern and mosaic pattern of lung attenuation $(\mathbf{E}, \mathbf{F})$. 
Chest CTPA is an imaging of choice for the diagnosis of APE, but CTPA alone cannot exclude or confirm CTEPH completely. In the current guidelines, V/Q lung scan still remains the first-line imaging modality for the detection of CTEPH because V/Q scans demonstrate better sensitivity and specificity for the diagnosis of CTEPH as compared to those of chest CTPA [3, 34]. Nevertheless, several findings of chest CTPA can be useful in differentiating CTEPH from APE and CTEPH. The eccentric wall-adherent or mural thrombi, which are often calcified, is a relatively specific finding of CTEPH on CTPA (Fig. 5A, B). Complete vessel cutoff with convex margin due to organized thrombi is another specific feature of $\mathrm{CTEPH}$, which is different from the concave margin of acute $\mathrm{PE}$ with a tapering of thrombus (Fig. 5C, D). An additional finding of CTEPH is the abrupt narrowing of the vessel distal to complete obstruction, due to contraction of the thrombus in chronic PE. Intraluminal webs or band and intimal irregularities by organized thrombi are not pathognomic but suggestive that findings with CTPA are consistent with CTEPH as well. In the chronic type of PE, development of collateral systemic circulation such as bronchial artery dilatation is frequently observed [35-37]. In addition, a non-uniform arterial perfusion pattern and mosaic pattern of lung attenuation can be observed on CTPA in CTEPH (Fig. 5E, F). When chest CTPA revealed these findings, the possibility of CTEPH should be carefully monitored even in patients who were first diagnosed as PE.

In summary, the role of chest CTPA in PE can be summarized as follows; 1 ) chest CTPA is a gold standard CV imaging for the evaluation of suspected $\mathrm{APE}$, and it has replaced the role of $\mathrm{V} / \mathrm{Q}$ scan in the diagnosis of APE; 2) chest CTPA is useful in the evaluation of RV dysfunction in APE and thus risk stratification or clinical decision making of therapeutic strategy, especially before performing TTE or when TTE is not available; 3 ) chest CTPA enables a quantitative assessment of pulmonary artery clot loads by using a scoring system and DECT allows an assessment of pulmonary parenchyma perfusion, but the significance of these techniques should be validated through larger, future studies; 4) several findings of CTPA can be useful in differentiating CTEPH from APE, even though a V/Q scan is an imaging of choice in the diagnosis of CTEPH.

\section{Nuclear imaging: Ventilation/ /perfusion scintigraphy}

$\mathrm{V} / \mathrm{Q}$ scan is an established diagnostic test for suspected $\mathrm{PE}$. The main finding of $\mathrm{V} / \mathrm{Q}$ scans in $\mathrm{PE}$ is that of perfusion $(\mathrm{Q})$ defect without corresponding ventilation $(\mathrm{V})$ defect, which is recognized as a $V / Q$ mismatch (Fig. 6). Interpretation of the V/Q scan is important, considering the fact that there are other medical conditions that might cause a V/Q mismatch, such as veno-occlusive disorder, vasculitis, congenital pulmonary vascular abnormalities, pulmonary artery sarcoma, fibrosing mediastinitis, malignancy and mediastinal lymphadenopathy. Currently, the modified PIOPED II and prospective investigative study of acute pulmonary embolism diagnosis (PISAPED) criteria are most commonly used in the interpretation, with a sensitivity of $85 \%$ vs. $80 \%$ and specificity of $93 \%$ vs. $97 \%$, respectively [38, 39].

These systems classify studies as high probability, very low probability, normal and non-diagnostic. Current guideline recommends excluding $\mathrm{PE}$ when the study has been classified as normal, and to confirm PE when the study has been classified as high probability [3].

Presently, the $\mathrm{V} / \mathrm{Q}$ scan is one of the most useful imaging modalities in screening CTEPH in patients with $\mathrm{PH}$ in the absence or disappearance of PE. In CTEPH, V/Q scans reveal at least one segmental perfusion defect despite normal ventilation. According to the current guidelines, V/Q scan is recommended as a first-line imaging modality for CTEPH, with 96-97\% sensitivity and 90-95\% specificity for diagnosis [3].

Recently, the introduction of single photon emission computed tomography (SPECT) into $\mathrm{V} / \mathrm{Q}$ scintigraphy has emerged, which enables defining the size and location of perfusion defects more accurately, using a three-dimensional imaging technique [40]. Accordingly, the diagnostic performance of SPECT V/Q has been increasing with higher reproducibility and lower indeterminate rate compared to V/Q scanning [41-43].

In summary, the role of the $\mathrm{V} / \mathrm{Q}$ scan can be summarized as follows; 1) V/Q scan has high diagnostic accuracy in the evaluation of PE; 2) V/Q scan is useful in the discrimination of CTEPH from $\mathrm{APE}$, and is recommended as a first-line diagnostic tool for CTEPH.

\section{Magnetic resonance pulmonary angiography}

Magnetic resonance pulmonary angiography (MRPA) is another non-invasive imaging modality that can provide information about not only morphological assessment, but also functional assessment in patients with PE. 


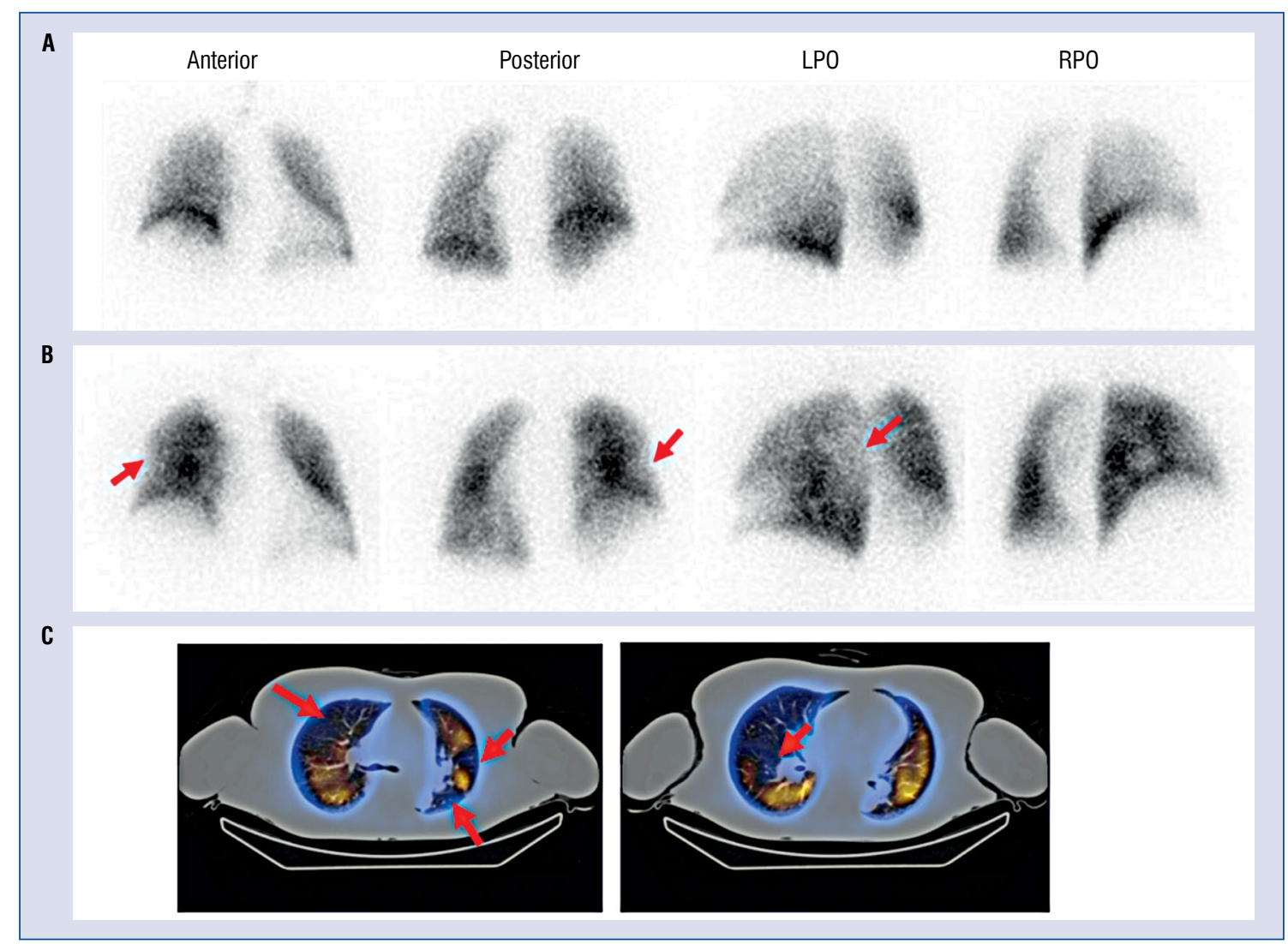

Figure 6. Ventilation/perfusion (V/Q) scans demonstrating pulmonary embolism. Moderate to large mismatch on $\mathrm{V} / \mathrm{Q}$ scan: normal ventilation scan $(\mathbf{A})$ and moderate-sized perfusion defect in right middle lung and large-sized perfusion defect in left upper lung on perfusion scan (B). A large-sized perfusion defect in right upper lung, and two, small-sized perfusion defects in left upper lung and a missed perfusion defect in anterior basal segment of right lower lung on perfusion planar image in perfusion single photon emission computed tomography-computed tomography (SPECT-CT; C); LPO — left posterior oblique; RPO — right posterior oblique.

With MRPA, vascular deformities such as vascular filling defects, complete absence of vessel enhancement, post-stenotic dilatation, and dilatation of a main pulmonary artery can be detected [44]. As with CTPA, irregular luminal filling defects, intraluminal webs and bands, vessel cutoffs and organized thrombi are indicative findings of CTEPH [45].

Recent research have shown that pulmonary artery flow can be assessed using phase contrast magnetic resonance [46]. Three- and four-dimensional phase contrast magnetic resonance imaging (MRI) provides visualization of vortex flow changes in pulmonary arteries [46, 47].

However, MRPA has lower sensitivity of PE compared to CTPA, especially in peripheral involvements [48]. The main advantages of MRPA are that it is free of ionizing radiation and can provide information on structure and flow mechanics [49-51].
Nevertheless, MRPA is not recommended for routine investigation of $\mathrm{PE}$, because of its limited availability, technically inadequate studies, reduced robustness and higher cost [3]. MRPA is anticipated as a promising imaging tool in the diagnosis of PE, however further studies are warranted for the clinical use of MRI in the diagnosis of PE.

\section{Role of conventional pulmonary angiography}

Pulmonary angiography provides direct visualization of obstructed vasculature or thrombi and also hemodynamic measurements [52]. It offers better visualization of peripheral pulmonary vessels, which can go undetected with other non-invasive imaging modalities, such as CTPA or MRPA. Filling defect or loss of pulmonary arterial branch is an indicative sign of PE. Currently, pulmonary angiography is more useful in patients suspected 
Table 2. Comparisons of various cardiovascular imaging modalities in the assessment of pulmonary embolism

\begin{tabular}{|c|c|c|}
\hline Modality & Advantages & Disadvantages \\
\hline $\begin{array}{l}\text { Transthoracic } \\
\text { echocardiography } \\
\text { (TTE) }\end{array}$ & $\begin{array}{l}\text { 1. Bedside evaluation is possible } \\
\text { 2. Useful in the evaluation of treatment } \\
\text { efficacy by serial exam } \\
\text { 3. Allows assessment of hemodynamics } \\
\text { 4. Relatively inexpensive cost } \\
\text { 5. Widely available equipment } \\
\text { 6. No radiation }\end{array}$ & $\begin{array}{l}\text { 1. Operator-dependent } \\
\text { 2. Cannot identify the thrombus extent } \\
\text { 3. High sensitivity, low specificity } \\
\text { 4. Suboptimal in patients with poor } \\
\text { imaging windows }\end{array}$ \\
\hline $\begin{array}{l}\text { Computed tomography } \\
\text { pulmonary angiography } \\
\text { (CTPA) }\end{array}$ & $\begin{array}{l}\text { 1. High diagnostic accuracy } \\
\text { 2. Diagnostic modality of choice } \\
\text { 3. Directly visualize the extent and } \\
\text { burden of the thrombus } \\
\text { 4. Visualize thromboembolic resolution } \\
\text { after treatment } \\
\text { 5. Allows assessment of other cardiac } \\
\text { structures }\end{array}$ & $\begin{array}{l}\text { 1. Radiation exposure } \\
\text { 2. Contrast administration precludes } \\
\text { use in patients with advanced } \\
\text { renal disease }\end{array}$ \\
\hline $\begin{array}{l}\text { Ventilation/perfusion } \\
\text { (V/Q) scan }\end{array}$ & $\begin{array}{l}\text { 1. High diagnostic accuracy } \\
\text { 2. Helps to distinguish CTEPH from } \\
\text { acute pulmonary embolism }\end{array}$ & $\begin{array}{l}\text { 1. Limited availability } \\
\text { 2. High cost } \\
\text { 3. Radiation exposure }\end{array}$ \\
\hline $\begin{array}{l}\text { Magnetic resonance } \\
\text { imaging (MRI) }\end{array}$ & $\begin{array}{l}\text { 1. Free from ionizing radiation } \\
\text { 2. Can provide information on } \\
\text { structure and flow mechanics }\end{array}$ & $\begin{array}{l}\text { 1. Limited availability } \\
\text { 2. Gadolinium administration } \\
\text { precludes use in patient with } \\
\text { advanced renal disease } \\
\text { 3. High cost }\end{array}$ \\
\hline
\end{tabular}

CTEPH — chronic thromboembolic pulmonary hypertension

for CTEPH. Similar to CTPA findings, complete vessel cutoff with convex contour of thrombi, abrupt vessel narrowing, luminal irregularity and intravascular bands or webs are indicative signs of CTEPH rather than APE [36].

In patients with APE with shock or hypotension, prompt catheter-directed thrombolysis or thrombectomy can be performed after diagnosis of APE. Otherwise in patients with $\mathrm{PH}$ with suspected CTEPH, pulmonary balloon angioplasty followed by diagnostic pulmonary angiography can be performed for PH relief [3, 34, 53, 54].

\section{Role of venous compression ultrasonography}

The role of lower extremity venous compression ultrasonography (CUS) in the routine diagnostic strategy is limited because of its low sensitivity for PE [3, 55].
With the advancements in technology, CTPA has shown better diagnostic performance in detecting PE compared to CUS [56]. However, it is useful to perform a CUS in diagnosing $\mathrm{PE}$, in cases where it is difficult to obtain CTPA, such as pregnant women, patients with chronic kidney disease or with an allergy to contrast media $[57,58]$.

\section{Imaging modalities in special cases}

\section{Pregnancy}

The imaging modality of choice in the diagnosis of deep vein thrombosis (DVT) of the lower limb in pregnancy is CUS. Abnormal D-dimer and proximal DVT founded by lower extremity compressive venous sonography warrants anticoagulation therapy and makes thoracic imaging unnecessary.

Guidelines recommend performing a V/Q scan over CTPA in the diagnosis of PE in pregnant women. The V/Q scan protocol can be adjusted to 
lower fetal and maternal radiation exposure. A low dose perfusion scan can be performed with a half dose of routine radiopharmaceutical agents. It is not fully established, but V/Q scan may offer less maternal radiation exposure and higher diagnostic accuracy compared to that of CTPA $[3,59,60]$.

\section{Impaired renal function}

Computed tomography pulmonary angiography is not a good option for the diagnosis of $\mathrm{PE}$ in patients with high risk for radio-contrast induced nephropathy. Magnetic resonance angiography carries a better renal safety profile and no radiation exposure [61]. However, gadolinium-related nephrogenic systemic fibrosis could occur [62]. $\mathrm{V} / \mathrm{Q}$ scan is preferred over CTPA in patients with impaired renal function and suspicions of $\mathrm{PE}$ to avoid contrast mediated injury of the kidneys [63].

\section{Conclusions}

Despite many advances in medical technology, there is still uncertainty about decisions in the diagnosis and prognosis of PE and treatment plans in clinical practice. A high index of clinical suspicion and selection and use of optimal CV imaging are essential in the diagnosis of PE. Physicians, therefore, should be familiar with the major advantages or pitfalls of various $\mathrm{CV}$ imaging modalities used in the evaluation of PE (Table 2). The optimal use of multimodality CV imaging enables the comprehensive assessment of anatomical and functional severity of $\mathrm{PE}$ and the prediction of prognosis as well as the decision for choosing therapeutic strategy.

\section{Conflict of interest: None declared}

\section{References}

1. Horlander KT, Mannino DM, Leeper KV. Pulmonary embolism mortality in the United States, 1979-1998: an analysis using multiple-cause mortality data. Arch Intern Med. 2003; 163(14): 1711-1717, doi: 10.1001/archinte.163.14.1711, indexed in Pubmed: 12885687.

2. Goldhaber SZ, Visani L, De Rosa M. Acute pulmonary embolism: clinical outcomes in the International Cooperative Pulmonary Embolism Registry (ICOPER). Lancet. 1999; 353(9162): 1386-1389, doi: 10.1016/s0140-6736(98)07534-5, indexed in Pubmed: 10227218.

3. Konstantinides SV, Torbicki A, Agnelli G, et al. 2014 ESC guidelines on the diagnosis and management of acute pulmonary embolism. Eur Heart J. 2014; 35(43): 3033-3069, doi: 10.1093/ eurheartj/ehu283, indexed in Pubmed: 25173341.

4. Vonk Noordegraaf A, Westerhof BE, Westerhof N. The Relationship Between the Right Ventricle and its Load in Pulmo- nary Hypertension. J Am Coll Cardiol. 2017; 69(2): 236-243, doi: 10.1016/j.jacc.2016.10.047, indexed in Pubmed: 28081831.

5. Kim NH, Delcroix M, Jais X, et al. Chronic thromboembolic pulmonary hypertension. Eur Respir J. 2019; 53(1), doi: 10.1183/13993003.01915-2018, indexed in Pubmed: 30545969 .

6. Kucher N, Rossi E, De Rosa M, et al. Prognostic role of echocardiography among patients with acute pulmonary embolism and a systolic arterial pressure of $90 \mathrm{~mm} \mathrm{Hg}$ or higher. Arch Intern Med. 2005; 165(15): 1777-1781, doi: 10.1001/ archinte.165.15.1777, indexed in Pubmed: 16087827.

7. Kucher N, Luder CM, Dörnhöfer T, et al. Novel management strategy for patients with suspected pulmonary embolism. Eur Heart J. 2003; 24(4): 366-376, doi: 10.1016/s0195668x(02)00476-1, indexed in Pubmed: 12581684.

8. McConnell MV, Solomon SD, Rayan ME, et al. Regional right ventricular dysfunction detected by echocardiography in acute pulmonary embolism. Am J Cardiol. 1996; 78(4): 469-473, doi: 10.1016/s0002-9149(96)00339-6, indexed in Pubmed: 8752195.

9. Platz E, Hassanein AH, Shah A, et al. Regional right ventricular strain pattern in patients with acute pulmonary embolism. Echocardiography. 2012; 29(4): 464-470, doi: 10.1111/j.15408175.2011.01617.x, indexed in Pubmed: 22276918.

10. Casazza F, Bongarzoni A, Capozi A, et al. Regional right ventricular dysfunction in acute pulmonary embolism and right ventricular infarction. Eur J Echocardiogr. 2005; 6(1): 11-14, doi: 10.1016/j.euje.2004.06.002, indexed in Pubmed: 15664548.

11. Seo HS, Lee H. Assessment of right ventricular function in pulmonary hypertension with multimodality imaging. J Cardiovasc Imaging. 2018; 26(4): 189-200, doi: 10.4250/jcvi.2018.26.e28, indexed in Pubmed: 30607386.

12. Lee JH, Park JH, Park KI, et al. A comparison of different techniques of two-dimensional speckle-tracking strain measurements of right ventricular systolic function in patients with acute pulmonary embolism. J Cardiovasc Ultrasound. 2014; 22(2): 65-71, doi: 10.4250/jcu.2014.22.2.65, indexed in Pubmed: 25031796.

13. Pruszczyk P, Goliszek S, Lichodziejewska B, et al. Prognostic value of echocardiography in normotensive patients with acute pulmonary embolism. JACC Cardiovasc Imaging. 2014; 7(6): 553-560, doi: 10.1016/j.jcmg.2013.11.004, indexed in Pubmed: 24412192.

14. Lee JH, Park JH. Role of echocardiography in patients with acute pulmonary thromboembolism. J Cardiovasc Ultrasound. 2008; 16(1): 9-16, doi: 10.4250/jcu.2008.16.1.9.

15. Roberts JD, Forfia PR. Diagnosis and assessment of pulmonary vascular disease by Doppler echocardiography. Pulm Circ. 2011; 1(2): 160-181, doi: 10.4103/2045-8932.83446, indexed in Pubmed: 22034604.

16. Stein PD, Fowler SE, Goodman LR, et al. Multidetector computed tomography for acute pulmonary embolism. N Engl J Med. 2006; 354(22): 2317-2327, doi: 10.1056/NEJMoa052367, indexed in Pubmed: 16738268.

17. Park JR, Chang SA, Jang SYi, et al. Evaluation of right ventricular dysfunction and prediction of clinical outcomes in acute pulmonary embolism by chest computed tomography: comparisons with echocardiography. Int J Cardiovasc Imaging. 2012; 28(4): 979-987, doi: 10.1007/s10554-011-9912-4, indexed in Pubmed: 21717126.

18. He H, Stein MW, Zalta B, et al. Computed tomography evaluation of right heart dysfunction in patients with acute pulmonary embolism. J Comput Assist Tomogr. 2006; 30(2): 262-266, 
doi: 10.1097/00004728-200603000-00018, indexed in Pubmed: 16628044.

19. Coutance G, Cauderlier E, Ehtisham J, et al. The prognostic value of markers of right ventricular dysfunction in pulmonary embolism: a meta-analysis. Crit Care. 2011; 15(2): R103, doi: 10.1186/cc10119, indexed in Pubmed: 21443777.

20. Becattini C, Agnelli G, Vedovati MC, et al. Multidetector computed tomography for acute pulmonary embolism: diagnosis and risk stratification in a single test. Eur Heart J. 2011; 32(13): 1657-1663, doi: 10.1093/eurheartj/ehr108, indexed in Pubmed: 21504936 .

21. Seon HJu, Kim KH, Lee WS, et al. Usefulness of computed tomographic pulmonary angiography in the risk stratification of acute pulmonary thromboembolism. Comparison with cardiac biomarkers. Circ J. 2011; 75(2): 428-436, doi: 10.1253/circj.cj10-0361, indexed in Pubmed: 21173497.

22. Schoepf UJ, Kucher N, Kipfmueller F, et al. Right ventricular enlargement on chest computed tomography: a predictor of early death in acute pulmonary embolism. Circulation. 2004; 110(20): 3276-3280, doi: 10.1161/01.CIR.0000147612.59751.4C, indexed in Pubmed: 15533868.

23. van der Meer RW, Pattynama PMT, van Strijen MJL, et al. Right ventricular dysfunction and pulmonary obstruction index at helical CT: prediction of clinical outcome during 3-month follow-up in patients with acute pulmonary embolism. Radiology. 2005; 235(3): 798-803, doi: 10.1148/radiol.2353040593, indexed in Pubmed: 15845793.

24. Miller GA, Sutton GC, Kerr IH, et al. Comparison of streptokinase and heparin in treatment of isolated acute massive pulmonary embolism. Br Med J. 1971; 2(5763): 681-684, doi: 10.1136/ bmj.2.5763.681, indexed in Pubmed: 5556052.

25. Qanadli SD, El Hajjam M, Vieillard-Baron A, et al. New CT index to quantify arterial obstruction in pulmonary embolism: comparison with angiographic index and echocardiography. AJR Am J Roentgenol. 2001; 176(6): 1415-1420, doi: 10.2214/ ajr.176.6.1761415, indexed in Pubmed: 11373204.

26. Mastora I, Remy-Jardin M, Masson P, et al. Severity of acute pulmonary embolism: evaluation of a new spiral CT angiographic score in correlation with echocardiographic data. Eur Radiol. 2003; 13(1): 29-35, doi: 10.1007/s00330-002-1515-y, indexed in Pubmed: 12541107.

27. Walsh P, Greenspan R, Simon M, et al. An angiographic severity index for pulmonary embolism. Circulation. 1973; 47(suppl2), doi: 10.1161/01.cir.47.4s2.ii-101.

28. Bankier AA, Janata K, Fleischmann D, et al. Severity assessment of acute pulmonary embolism with spiral CT: evaluation of two modified angiographic scores and comparison with clinical data. J Thorac Imaging. 1997; 12(2): 150-158, indexed in Pubmed: 9179827.

29. Collomb D, Paramelle PJ, Calaque O, et al. Severity assessment of acute pulmonary embolism: evaluation using helical CT. Eur Radiol. 2003; 13(7): 1508-1514, doi: 10.1007/s00330-002-1804-5, indexed in Pubmed: 12835961.

30. Araoz PA, Gotway MB, Trowbridge RL, et al. Helical CT pulmonary angiography predictors of in-hospital morbidity and mortality in patients with acute pulmonary embolism. J Thorac Imaging. 2003; 18(4): 207-216, indexed in Pubmed: 14561905.

31. Ghaye B, Ghuysen A, Willems V, et al. Severe pulmonary embolism:pulmonary artery clot load scores and cardiovascular parameters as predictors of mortality. Radiology. 2006; 239(3): 884-891, doi: 10.1148/radiol.2392050075, indexed in Pubmed: 16603659 .
32. Vedovati MC, Germini F, Agnelli G, et al. Prognostic role of embolic burden assessed at computed tomography angiography in patients with acute pulmonary embolism: systematic review and meta-analysis. J Thromb Haemost. 2013; 11(12): 2092-2102, doi: 10.1111/jth.12429, indexed in Pubmed: 24134450.

33. Renard B, Remy-Jardin M, Santangelo T, et al. Dual-energy CT angiography of chronic thromboembolic disease: can it help recognize links between the severity of pulmonary arterial obstruction and perfusion defects? Eur J Radiol. 2011; 79(3): 467-472, doi: 10.1016/j.ejrad.2010.04.018, indexed in Pubmed: 20488639.

34. Galiè N, Humbert M, Vachiery JL, et al. 2015 ESC/ERS Guidelines for the diagnosis and treatment of pulmonary hypertension: The Joint Task Force for the Diagnosis and Treatment of Pulmonary Hypertension of the European Society of Cardiology (ESC) and the European Respiratory Society (ERS): Endorsed by: Association for European Paediatric and Congenital Cardiology (AEPC), International Society for Heart and Lung Transplantation (ISHLT). Eur Heart J. 2016; 37(1): 67-119, doi: 10.1093/ eurheartj/ehv317, indexed in Pubmed: 26320113.

35. Reichelt A, Hoeper MM, Galanski M, et al. Chronic thromboembolic pulmonary hypertension: evaluation with 64-detector row CT versus digital substraction angiography. Eur J Radiol. 2009; 71(1): 49-54, doi: 10.1016/j.ejrad.2008.03.016, indexed in Pubmed: 18462902.

36. Wittram C, Kalra MK, Maher MM, et al. Acute and chronic pulmonary emboli: angiography-CT correlation. AJR Am J Roentgenol. 2006; 186(6 Suppl 2): S421-S429, doi: 10.2214/ AJR.04.1955, indexed in Pubmed: 16714619.

37. Hasegawa I, Boiselle PM, Hatabu H. Bronchial artery dilatation on MDCT scans of patients with acute pulmonary embolism: comparison with chronic or recurrent pulmonary embolism. AJR Am J Roentgenol. 2004; 182(1): 67-72, doi: 10.2214/ ajr.182.1.1820067, indexed in Pubmed: 14684514.

38. Anderson DR, Barnes DC. Computerized tomographic pulmonary angiography versus ventilation perfusion lung scanning for the diagnosis of pulmonary embolism. Curr Opin Pulm Med. 2009; 15(5): 425-429, doi: 10.1097/MCP.0b013e32832d6b98, indexed in Pubmed: 19465853.

39. Sostman HD, Miniati M, Gottschalk A, et al. Sensitivity and specificity of perfusion scintigraphy combined with chest radiography for acute pulmonary embolism in PIOPED II. J Nucl Med. 2008; 49(11): 1741-1748, doi: 10.2967/jnumed.108.052217, indexed in Pubmed: 18927339.

40. Roach PJ, Schembri GP, Bailey DL. V/Q scanning using SPECT and SPECT/CT. J Nucl Med. 2013; 54(9): 1588-1596, doi: 10.2967/jnumed.113.124602, indexed in Pubmed: 23907760.

41. Roach PJ, Bailey DL, Harris BE. Enhancing lung scintigraphy with single-photon emission computed tomography. Semin Nucl Med. 2008; 38(6): 441-449, doi: 10.1053/j.semnuclmed.2008.06.002, indexed in Pubmed: 19331838.

42. Gutte H, Mortensen J, Jensen CV, et al. Detection of pulmonary embolism with combined ventilation-perfusion SPECT and low-dose CT: head-to-head comparison with multidetector CT angiography. J Nucl Med. 2009; 50(12): 1987-1992, doi: 10.2967/ jnumed.108.061606, indexed in Pubmed: 19910421.

43. Bajc M, Neilly JB, Miniati M, et al. EANM guidelines for ventilation/perfusion scintigraphy : Part 1. Pulmonary imaging with ventilation/perfusion single photon emission tomography. Eur J Nucl Med Mol Imaging. 2009; 36(8): 1356-1370, doi: 10.1007/ s00259-009-1170-5, indexed in Pubmed: 19562336.

44. Kalb B, Sharma P, Tigges S, et al. MR imaging of pulmonary embolism: diagnostic accuracy of contrast-enhanced 3D MR pul- 
monary angiography, contrast-enhanced low-flip angle 3D GRE, and nonenhanced free-induction FISP sequences. Radiology. 2012; 263(1): 271-278, doi: 10.1148/radiol.12110224, indexed in Pubmed: 22438448.

45. Kreitner KFJ, Ley S, Kauczor HU, et al. Chronic thromboembolic pulmonary hypertension: pre- and postoperative assessment with breath-hold MR imaging techniques. Radiology. 2004; 232(2): 535-543, doi: 10.1148/radiol.2322030945, indexed in Pubmed: 15215554.

46. Kawakubo M, Akamine H, Yamasaki Y, et al. Three-dimensional phase contrast magnetic resonance imaging validated to assess pulmonary artery flow in patients with chronic thromboembolic pulmonary hypertension. Radiol Phys Technol. 2017; 10(2): 249-255, doi: 10.1007/s12194-016-0383-0, indexed in Pubmed: 27783357.

47. Ota H, Sugimura K, Miura M, et al. Four-dimensional flow magnetic resonance imaging visualizes drastic change in vortex flow in the main pulmonary artery after percutaneous transluminal pulmonary angioplasty in a patient with chronic thromboembolic pulmonary hypertension. Eur Heart J. 2015; 36(25): 1630, doi: 10.1093/eurheartj/ehv054, indexed in Pubmed: 25736251.

48. Huisman MV, Klok FA. Magnetic resonance imaging for diagnosis of acute pulmonary embolism: not yet a suitable alternative to CTPA. J Thromb Haemost. 2012; 10(5): 741-742, doi: 10.1111/j.15387836.2012.04678.x, indexed in Pubmed: 22375614.

49. Ley S, Grünig E, Kiely DG, et al. Computed tomography and magnetic resonance imaging of pulmonary hypertension: Pulmonary vessels and right ventricle. J Magn Reson Imaging. 2010; 32(6): 1313-1324, doi: 10.1002/jmri.22373, indexed in Pubmed: 21105137.

50. Kreitner KF, Kunz RP, Ley S, et al. Chronic thromboembolic pulmonary hypertension - assessment by magnetic resonance imaging. Eur Radiol. 2007; 17(1): 11-21, doi: 10.1007/s00330006-0327-x, indexed in Pubmed: 16838142.

51. Reiter U, Reiter G, Fuchsjäger M. MR phase-contrast imaging in pulmonary hypertension. Br J Radiol. 2016; 89(1063): 20150995, doi: 10.1259/bjr.20150995.

52. Dalen J, Brooks H, Johnson L, et al. Pulmonary angiography in acute pulmonary embolism: Indications, techniques, and results in 367 patients. Am Heart J. 1971; 81(2): 175-185, doi: 10.1016/0002-8703(71)90128-1.

53. Kim NH, Delcroix M, Jais X, et al. Chronic thromboembolic pulmonary hypertension. J Am Coll Cardiol. 2013; 62(25 Suppl): D92-D99, doi: 10.1016/j.jacc.2013.10.024, indexed in Pubmed: 24355646 .
54. Kataoka M, Inami T, Kawakami T, et al. Balloon pulmonary angioplasty (percutaneous transluminal pulmonary angioplasty) for chronic thromboembolic pulmonary hypertension: a japanese perspective. JACC Cardiovasc Interv. 2019; 12(14): 1382-1388, doi: 10.1016/j.jcin.2019.01.237, indexed in Pubmed: 31103538.

55. Da Costa Rodrigues J, Alzuphar S, Combescure C, et al. Diagnostic characteristics of lower limb venous compression ultrasonography in suspected pulmonary embolism: a meta-analysis. J Thromb Haemost. 2016; 14(9): 1765-1772, doi: 10.1111/ jth.13407, indexed in Pubmed: 27377039.

56. Righini M, Le Gal G, Aujesky D, et al. Diagnosis of pulmonary embolism by multidetector CT alone or combined with venous ultrasonography of the leg: a randomised non-inferiority trial. Lancet. 2008; 371(9621): 1343-1352, doi: 10.1016/S01406736(08)60594-2, indexed in Pubmed: 18424324.

57. Elias A, Colombier D, Victor G, et al. Diagnostic performance of complete lower limb venous ultrasound in patients with clinically suspected acute pulmonary embolism. Thromb Haemost. 2004; 91(1): 187-195, doi: 10.1160/TH03-05-0278, indexed in Pubmed: 14691585.

58. Righini M, Le Gal G, Aujesky D, et al. Complete venous ultrasound in outpatients with suspected pulmonary embolism. J Thromb Haemost. 2009; 7(3): 406-412, doi: 10.1111/j.15387836.2008.03264.x, indexed in Pubmed: 19143927.

59. Wan T, Skeith L, Karovitch A, et al. Guidance for the diagnosis of pulmonary embolism during pregnancy: Consensus and controversies. Thromb Res. 2017; 157: 23-28, doi: 10.1016/j. thromres.2017.06.025, indexed in Pubmed: 28686913.

60. Chan WS, Rey E, Kent NE, et al. Venous thromboembolism and antithrombotic therapy in pregnancy. J Obstet Gynaecol Can. 2014; 36(6): 527-553, indexed in Pubmed: 24927193.

61. Pleszewski B, Chartrand-Lefebvre C, Qanadli SD, et al. Gadolinium-enhanced pulmonary magnetic resonance angiography in the diagnosis of acute pulmonary embolism: a prospective study on 48 patients. Clin Imaging. 2006; 30(3): 166-172, doi: 10.1016/j. clinimag.2005.10.005, indexed in Pubmed: 16632150.

62. Thomsen HS. Nephrogenic systemic fibrosis: a serious adverse reaction to gadolinium - 1997-2006-2016. Part 1. Acta Radiol. 2016; 57(5): 515-520, doi: 10.1177/0284185115626480, indexed in Pubmed: 26802069.

63. Miniati M, Sostman HD, Gottschalk A, et al. Perfusion lung scintigraphy for the diagnosis of pulmonary embolism: a reappraisal and review of the Prospective Investigative Study of Acute Pulmonary Embolism Diagnosis methods. Semin Nucl Med. 2008; 38(6): 450-461, doi: 10.1053/j.semnuclmed.2008.06.001, indexed in Pubmed: 19331839. 